\title{
A Decade of Growth
}

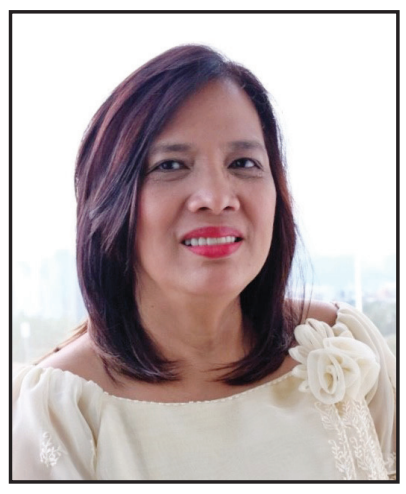

As the official journal of the ASEAN Federation of Endocrine Societies (AFES) of Indonesia, Malaysia, Philippines, Singapore, Thailand, Vietnam, and Myanmar, JAFES has, since 1982, served as the voice of researchers and clinicians on endocrinology, diabetes, and metabolism in our region. This first issue for 2021 marks the $11^{\text {th }}$ year since we revitalized the journal. With sustained AFES support; steady contributions of our editors and peer reviewers; and renewed interest of investigators and authors, we managed our growing pains and learned critical lessons. Our logo aptly depicts the growing tree as a "symbol of family, a common root spreading out into our rich soil, our cultural heritage that is distinctly Southeast Asian" (Figure 1). ${ }^{1}$

Over the last 10 years, JAFES has grown into an internationally recognized, world-class publication, incorporating best practices on scholarly research. We are $100 \%$ open access, making all the science available and accessible to everyone, without asking for subscription or download fees, without levying any article processing charges to submitting authors. JAFES has invested in information-technology driven tools and applications to provide articles that are easily searchable, reader-friendly, and permanent in the online scholarly publishing ecosystem. We put a premium on ethical research, subscribing to international reporting standards. We have improved the communication of findings by converting original articles to visual abstracts that are promoted through social media for both practitioners and lay readers, to enhance patient education. ${ }^{2}$ We are proud to say that we are among the pioneers in the region. We look forward to an evaluation of these processes, to help us improve further.

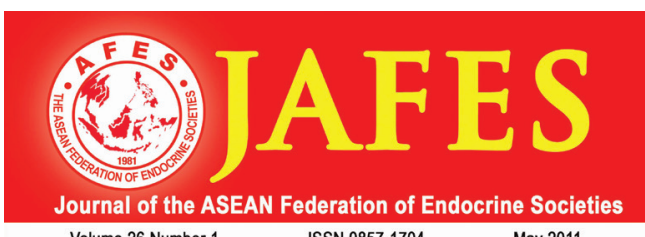
Volume 26 Number $1 \quad$ ISSN 0857-1704 May 2011

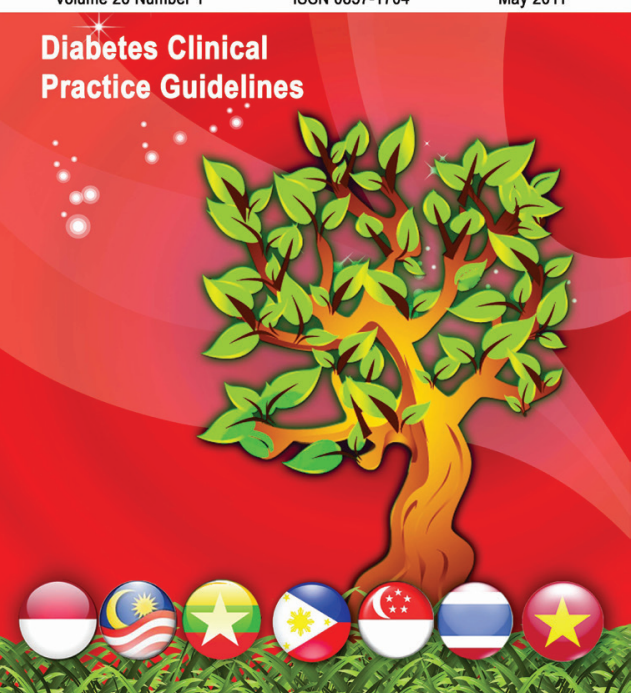

Figure 1. JAFES Vol. 26 No. 1, May 2011 first issue cover designed by Dr. Mia C. Fojas.

JAFES is now indexed in PubMed Central, Scopus ${ }^{\mathrm{TM}}$ and Web of Science ${ }^{\mathrm{TM}}$ as well as the Western Pacific Region Index Medicus and Directory of Open Access Journals. Indeed, ensuring the visibility of our authors' outputs is a top priority of JAFES.

Relevance and applicability of our publication to our patients in the region is the key goal. We have been highlighting themes of crucial value, starting off with diabetes and the metabolic syndrome, where rates in the region are clearly increasing, occurring at a younger age and with visceral obesity, phenotypes different from our Western counterparts. We have also focused on country practice guidelines, as an initial step towards collaboration within the leaders in the AFES countries. As the COVID-19 pandemic occurred in 2020, AFES editors also initiated a survey on ASEAN needs, with the intent of providing a platform for discussions on these interim reports and practices. We are, in a longerterm view, recognizing the need for understanding endocrine conditions at another level, encouraging molecular and "-omics" research in the region. 
Borrowing words from my editorial five years ago, "We feel nostalgic looking back at the work accomplished and the work at hand. With unwavering passion, we reared the journal like our child, full of ambition and hope, celebrating small victories, committing some mistakes in the process, but learning, continually learning, as we go. Each issue, a genuine product of sleepless editorial nights, was like a milestone, from learning to sit to learning to crawl, from crawling to pulling to stand, from standing to finally taking one step, two steps then three." ${ }^{3}$ Both as the child and the tree, with commitment and care by AFES, JAFES continues to grow.

\section{Elizabeth Paz-Pacheco Editor-in-Chief}

\section{Postscript:}

We are dedicating this issue to Dr. Jose Ma. C. Avila who passed away this year. He was instrumental in providing vital foundations for the revitalized journal, guiding us on the editorial process and teaching us how to manage the journal's operations. Joey was a classmate from medical school, a good friend, a university professor, a leader in Pathology. For this, we will always be grateful.

\section{References}

1. Tangco RV. About the Cover. J ASEAN Fed Endocr Soc.2011;26(1):2. https://doi.org/10.15605/jafes.026.01.

2. Tandoc III AO. Our Commitment to Authors and Readers. J ASEAN Fed Endocr Soc. 26 November 2019. YouTube video, 2:30. https://www.youtube.com/watch? $v=33 Z$ uHN0r7IQ\&t=8s.

3. Paz-Pacheco E. Full Circle. J ASEAN Fed Endocr Soc. 2015;30(2):91-2. https://doi.org/10.15605/jafes.030.02.18.

https://doi.org/10.15605/jafes.036.01.17 